\title{
Geoturismo: proposta de valorização e sustentabilidade territorial alternativa ao turismo de "sol e praia" no litoral sul de Pernambuco - Brasil
}

\author{
Geotourism: proposed of valorization and territorial sustainability alternative to \\ the tourism of "sun and beach" on the southern coast of Pernambuco - Brazil
}

Thaís Oliveira Guimarães ${ }^{a}$

Gorki Mariano $^{b}$

Artur Agostinho Abreu Sác aDoutora em Geociências pela Universidade Federal de
Pernambuco.

${ }^{\mathrm{b}}$ Professor titular do Departamento de Geologia da Universidade Federal de Pernambuco; Doutor em Geologia.

'Professor Associado da Escola de Ciências da Vida e do Ambiente na Universidade de Trás-os-Montes e Alto-Douro - Portugal; Doutor em Geociências.

Recebido em: 23/05/2017 I Aceito em: 07/06/2017

\section{RESUMO}

O Litoral Sul do Estado de Pernambuco compreende uma extensão de praias de $110 \mathrm{~km}$, composta por sete municípios (Cabo de Santo Agostinho, Ipojuca, Sirinhaém, Rio Formoso, Tamandaré, Barreiros e São José da Coroa Grande). A região destaca-se por meio de sua configuração geológica, localização geográfica, ocorrências históricas e a atividade turística. Há milhões de anos a região foi palco de um dos grandes eventos tectônicos da história geológica da Terra, como a separação do mega continente Gondwana e consequente formação dos continentes Sul-americano e Africano ao fim do Período Cretáceo. Tais acontecimentos, associados aos processos exógenos ao longo de milhões de anos resultaram na atual configuração geológica e geomorfológica, representadas principalmente por rochas magmáticas (plutônicas e vulcânicas) e sedimentares que diferenciam a paisagem local, com destaque para o promontório do Cabo, afloramentos de arenito de praia, piscinas naturais, estuários, entre outros. Associada a um patrimônio geológico de relevância global, o Litoral Sul de Pernambuco coleciona importantes eventos históricos, 
forte cultura local e comunidades tradicionais. A localização geográfica privilegiada Ihe permite ainda sol durante todas as estações do ano. Tal cenário propiciou o desenvolvimento da atividade turística de "sol e praia", que teve início na década de 1940 a partir do turismo de segunda residência. O presente trabalho destaca as principais características físicas e sociais do litoral sul de Pernambuco, expõe uma breve análise sobre a atividade turística atual na região e apresenta uma proposta de valorização ao turismo já existente, esta agora baseada nos pilares do patrimônio natural, geoconservação e desenvolvimento territorial sustentável.

Palavras chave: Geodiversidade. Geoturismo. Desenvolvimento Sustentável. Geoconservação. Popularização das Geociências.

\begin{abstract}
The southerncoast of theState of Pernambuco comprisesanextension of $110 \mathrm{~km}$ and includes sevenmunicipalities (Cabo de Santo Agostinho, Ipojuca, Sirinhaém, Rio Formoso, Tamandaré, Barreiros and São José da Coroa Grande). The region stands out through its geological setting, geographical location, historical events and tourism activities. Millions of years ago the region was the scene of a major tectonic events of geological history of the Earth: the separation of the mega continent Gondwana and consequent formation of South American and African continents at the end of the Cretaceous Period. Such events, associated with the exogenous processes over millions of years resulted in the current geological and geomorphological setting, represented primarily by magmatic (plutonic and volcanic) and sedimentary rocks in contrast with the local landscape, with highlighting for the Cape promontory, outcrops of beachrocks, natural pools, estuaries, among others. Associated with a geological heritage of global relevance the southern coast of Pernambuco collects important historical events, strong local culture and traditional communities. The privileged geographical location brings sun shining during all seasons of the year. Such scenario led to the development of tourism of "sun and beach", which began in late 1940s like second home tourism. This paper highlights the main social and physical characteristics of the southern coast of Pernambuco, making a brief analysis of the current tourist activity in the region and presenting a proposed enhancement to the existing tourism, currently based on natural heritage, sustainable territorial development and geoconservation.
\end{abstract}

Keywords: Geoconservation. Geodiversidy. Geotourism. Popularization of geosciences. SustainableDevelopment

\title{
1 INTRODUÇÃO
}

O meio natural compreende essencialmente todos os elementos bióticos (com vida) e abióticos (sem vida) do planeta, bem como os processos a ele relacionados. Nesse sentido, entende-se por biodiversidade os elementos vivos presentes na Terra e por geodiversidade os elementos abióticos, que por sua vez, não possuem vida.

Vê-se ao longo das últimas décadas um grande apelo à preservação e conservação do "meio ambiente", mas o próprio termo já deixa a desejar e converge

Ciência e Sustentabilidade - CeS / Juazeiro do Norte, v. 3, n. 1, p. 33-57, jan/jun 2017 
para uma fragmentação do meio natural. Nesse sentido, Boff (2000) ressalta essa segregação do "meio" ambiente e expressa seu desejo por um ambiente inteiro.

O avanço na valorização e crescimento das discussões a cerca da geodiversidade, de seus valores e direta influência na biodiversidade ainda precisam atingir patamares maiores. Por outro lado, mesmo que a biodiversidade ainda tenha uma maior influência e atenção às medidas conservacionistas, a geodiversidade já tem começado a conquistar seu devido lugar, sendo destaque em projetos e programas mundialmente importantes como, por exemplo, o Programa Internacional de Geociências e geoparques, onde se incluem os Geoparques Mundiais da UNESCO que têm no patrimônio geológico um de seus principais pilares estruturantes.

Nesse sentindo, o presente trabalho apresenta duas questões relevantes: primeiro a valorização da geodiversidade e do patrimônio geológico e, segundo, a utilização desses elementos enquanto recurso para o desenvolvimento territorial sustentável.

Para isso foi realizado um estudo de caso, onde foi analisado o turismo de sol e praia já consolidado em toda a faixa litorânea sul do Estado de Pernambuco. Em paralelo, foram realizadas visitas e análises em territórios onde a prática do geoturismo já está implantada.

Com base nos resultados das referidas pesquisas foi identificado que a 0 Litoral Sul de Pernambuco apresenta o potencial necessário para tal prática, não apenas encaixando-se nos conceitos de geoturismo existentes na literatura, como apresentando características muito semelhantes aos territórios que trabalham sobre pilares da atividade geoturística, ou seja: i) alto índice de geodiversidade; ii) patrimônio geológico de relevância global; iii) importantes acontecimentos históricos e achados arqueológicos; iv) forte cultura local; v) comunidades tradicionais; vi) beleza cênica; vii) potencial turístico; viii) relevância didática e científica.

\section{METODOLOGIA}

Trata-se de uma pesquisa descritiva, exploratória e estudo de caso, tendo como objeto principal o patrimônio geológico previamente identificado na faixa 
costeira do Litoral Sul de Pernambuco (Zona Costeira Sul de Pernambuco) em conjunto com todas as relações socioambientais e valores a ele agregados (GUIMARÃES, 2016).

Está fundamentada em três pilares principais, denominados como categorias de análise: (1) Patrimônio natural (geológico-geomorfológico); (2) Geoconservação e (3) Desenvolvimento territorial sustentável, proposto por meio do geoturismo.

Tais critérios de seleção justificam-se diante da possibilidade de utilizar e conservar o patrimônio natural, histórico e cultural para esta geração e às gerações futuras, bem como, possibilitar uma melhor qualidade de vida à sociedade envolvida.

Para a obtenção dos resultados foi realizada exaustiva pesquisa bibliográfica, incursões a campo, visitas a regiões e territórios onde são trabalhados os pilares do geoturismo e realizado todo um levantamento fotográfico local e dos territórios visitados.

\section{RESULTADOS E DISCUSSÕES}

\subsection{Geodiversidade e patrimônio geológico: bases para o geoturismo}

O termo geodiversidade torna-se público em contraponto ao já estabelecido conceito de biodiversidade, referindo-se, aos elementos abióticos do planeta. Para Stanley (2000) a geodiversidade reúne uma variedade de ambientes geológicos, conjunto de processos e fenômenos que originam as paisagens, rochas, minerais, fósseis, solos e outros depósitos superficiais que constituem o suporte a vida no planeta.

Tal definição é utilizada pela Royal Society for NatureConservationdo Reino Unido. De acordo com o autor supracitado a geodiversidade compreende a ligação entre pessoas, paisagens e suas culturas, através da interação com a biodiversidade.

O termo pode ainda ser entendido como: "Variedade natural de aspectos geológicos (minerais, rochas e fósseis), geomorfológicos (formas de relevo e processos) e do solo. Incluindo suas coleções, propriedades interpretações e sistemas" (GRAY, 2004, p. 8.). Para Sharples (2002) a geodiversidade inclui 
elementos da geologia, geomorfologia, suas inter-relações, sistemas e processos do solo.

Segundo Brilha (2005) a geodiversidade é compreendida como sendo determinante para a evolução da civilização, desde a disponibilidade de alimento, as condições climáticas, abrigos e material para construção. Estruturas de defesa como castelos e fortes construídos em cotas topográficas mais elevadas estrategicamente estão diretamente relacionadas à geodiversidade.

É como se o patrimônio construído fosse um "espelho" da geodiversidade local, uma vez que as construções tradicionais se utilizam das rochas existentes na região. Esse fato é facilmente observado em várias regiões do globo, a exemplo da área em estudo, onde foram construídas, entre o século XVII e XIX fortificações com rochas extraídas da própria área e edificadas sobre os afloramentos rochosos (Fig. 1).

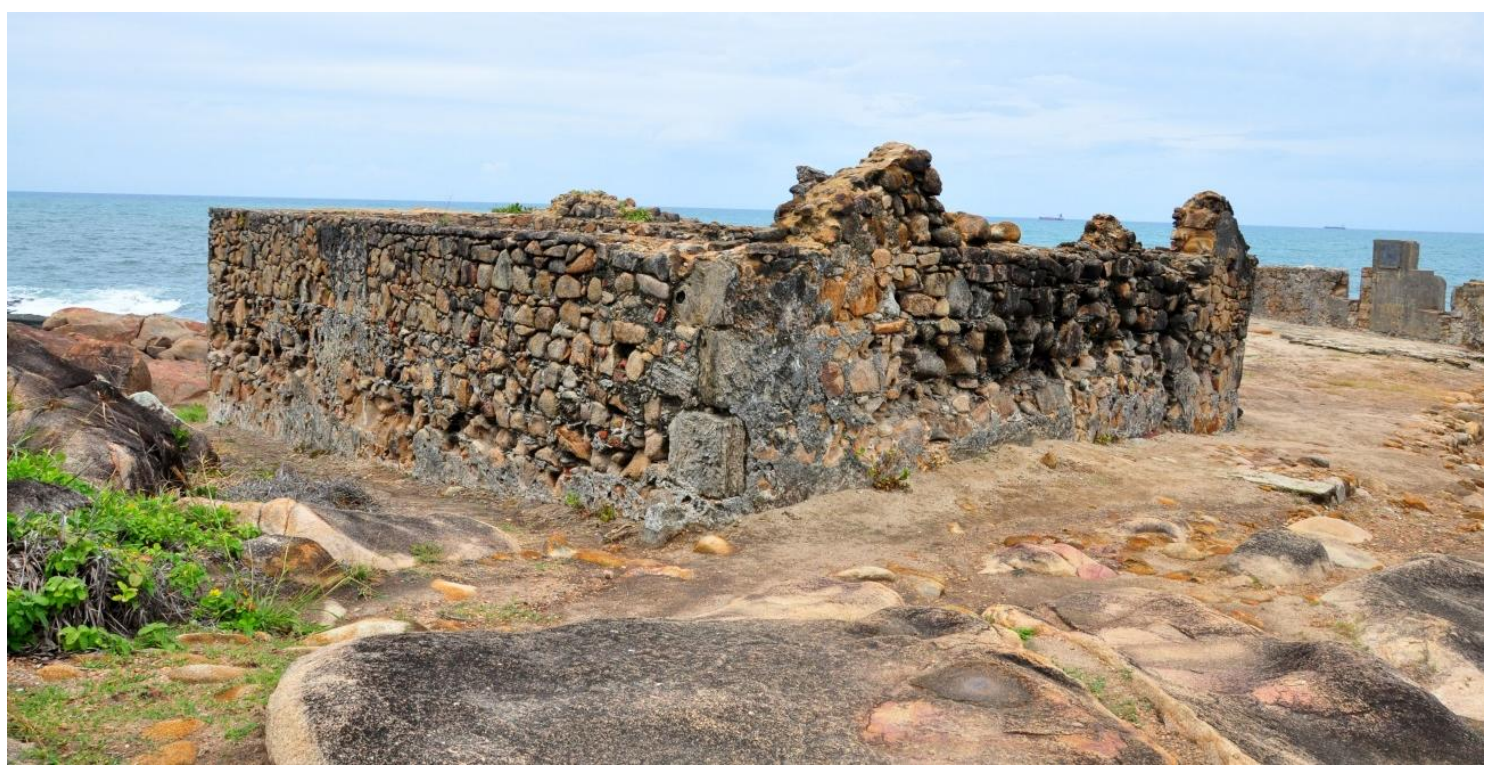

Figura 1: Ruínas do Forte Castelo do Mar (Séc. XVII) construídas basicamente com blocos graníticos provenientes do granito do Cabo e edificada sobre o próprio afloramento - Cabo de Santo Agostinho (@Thaís Guimarães, 2014).

Em uma visão integradora do meio abiótico, Kozlowski (2004) definiu a geodiversidade como um conjunto espacialmente complexo, composto pela epigeosfera (esfera exterior da Terra ou superfície terrestre) e a troposfera. Para o autor trata-se de um conjunto de esferas como a atmosfera, litosfera e hidrosfera, por exemplo. Ou seja, toda variedade natural da Terra, seja ela geológica, geomorfológica, solos, águas superficiais, bem como outros sistemas, resultantes de processos endógenos e exógenos, além de processos provenientes da atividade Ciência e Sustentabilidade - CeS / Juazeiro do Norte, v. 3, n. 1, p. 33-57, jan/jun 2017 
humana. O autor vai além do reducionismo da geodiversidade em "diversidade de elementos geológicos" e eleva a discussão a um patamar mais holístico e sistêmico (GUIMARÃES, 2016).

Gray (2005) defendeu que a geodiversidade permite incluir a diversidade natural na conservação, no planejamento e educação através de diferentes formas, por exemplo: geossítios, patrimônio geológico, geoparques e áreas protegidas.

Nesse sentido, vê-se o quão importante pode ser a geodiversidade quando integrada a ações profissionais de planejamento, conservação, proteção ou educação e utilizada como uma ferramenta científica para ser rigorosamente aplicada, juntamente com a biodiversidade à gestão do território e das paisagens (SERRANO; RUIZ-FLANO, 2007).

Zwolinski (2016) destacou que o trabalho de avaliação da geodiversidade deve ser considerado como uma fase inicial das pesquisas e que a partir dos avanços das metodologias de avaliação podem torná-la um indicador tão importante quanto à biodiversidade, podendo ser aplicada em vários ramos da ciência, como na geoconservação, por exemplo.

Para isso, foi realizada no Litoral Sul de Pernambuco uma análise descritiva dos principais elementos da geodiversidade e elaborado um inventário do patrimônio geológico, com a identificação e descrição de 13 geossítios, entre os municípios do Cabo de Santo Agostinho e São José da Coroa Grande (GUIMARÃES, 2016) (Fig. 2). 


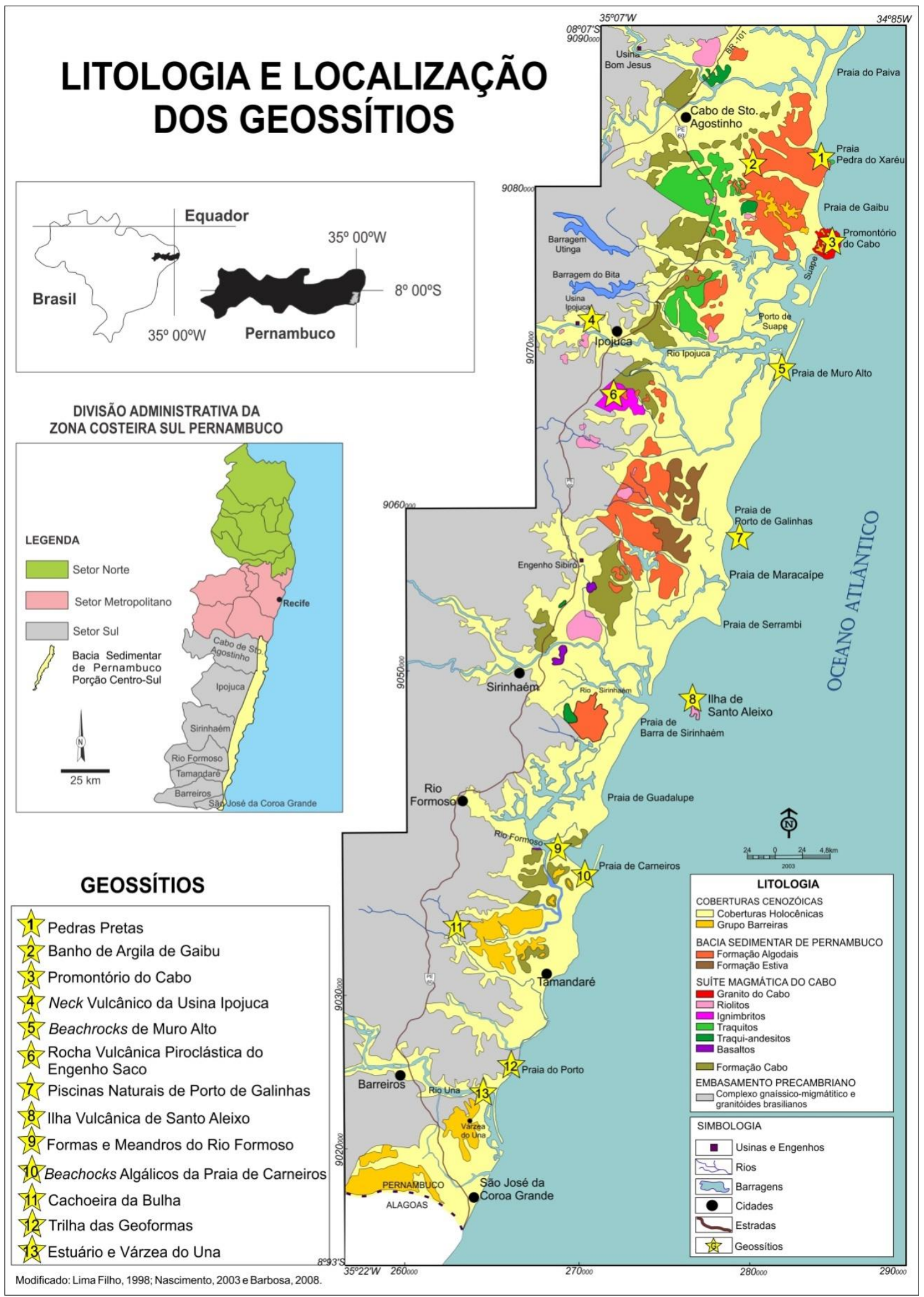

Figura 2: Localização da área de trabalho e dos geossítios inventariados por Guimarães (2016). Detalhe para o mapa litológico da Bacia Sedimentar de Pernambuco e Suíte Magmática Ipojuca (Fonte: Guimarães, 2016; modificado de CPRM, 2001; Nascimento, 2004; Barbosa, 2008). 


\subsection{Geoturismo: Subsídio a Geoconservação e sustentabilidade}

O geoturismo se apresenta como um importante instrumento de geoconservação, difusão do conhecimento e desenvolvimento territorial sustentável, tendo como objetivos: divulgar, valorizar e conservar os elementos naturais do meio abiótico.

Os principais atrativos da atividade são as formações geológicas, formas geomorfológicas, fósseis e icnofósseis, as paisagens, mas ao contrário do que o prefixo "geo" a princípio infere, vão muito mais além. Agregado ao lazer da atividade geoturística estão interesses didáticos, científicos, históricos e arqueológicos (Fig. $3)$.

Para Buckley (2003) o mais antigo uso do termo geoturismo correspondia ao turismo geológico, referindo-se as pessoas que viajavam para "ver rochas". Eventualmente, questiona-se a similaridade da atividade turística com ecoturismo. Notadamente, semelhanças existem, embora os princípios do geoturismo se apresentam de maneira bem diferente.

O pesquisador inglês Thomas Hose foi precursor a definir o conceito de geoturismo como a "provisão de serviços e facilidades interpretativas no sentido de possibilitar aos turistas a compreensão e aquisição de conhecimentos de um sítio geológico e geomorfológico ao invés da simples apreciação estética" (HOSE, 1995, p. 17).

Esta primeira proposta do autor supracitado vai além da simples contemplação e apreciação da paisagem ou da natureza, princípios estes, propostos pelo ecoturismo. São necessários conhecimento, interesse e informação. No ano 2000, Hose reformulou o conceito e definiu o geoturismo como:

\footnotetext{
(...) disponibilização de serviços e meios interpretativos que promovem o valor e os benefícios sociais de sítios com interesse geológico e geomorfológico, assegurando a sua conservação para o uso de estudantes, turistas e outras pessoas com interesse recreativo ou lazer (HOSE, 2000, p. 136).
}

Em território nacional o geoturismo foi apresentado por Piekarz e Liccardo (2007) como um elo com o ecoturismo, decorrente do contato com a natureza e a busca pelas experiências e sensações. Os autores ressaltam o turismo cultural como 
ponto em comum, uma vez que ambos agregam à atividade turística, visitas aos museus, igrejas e patrimônios arquitetônicos.
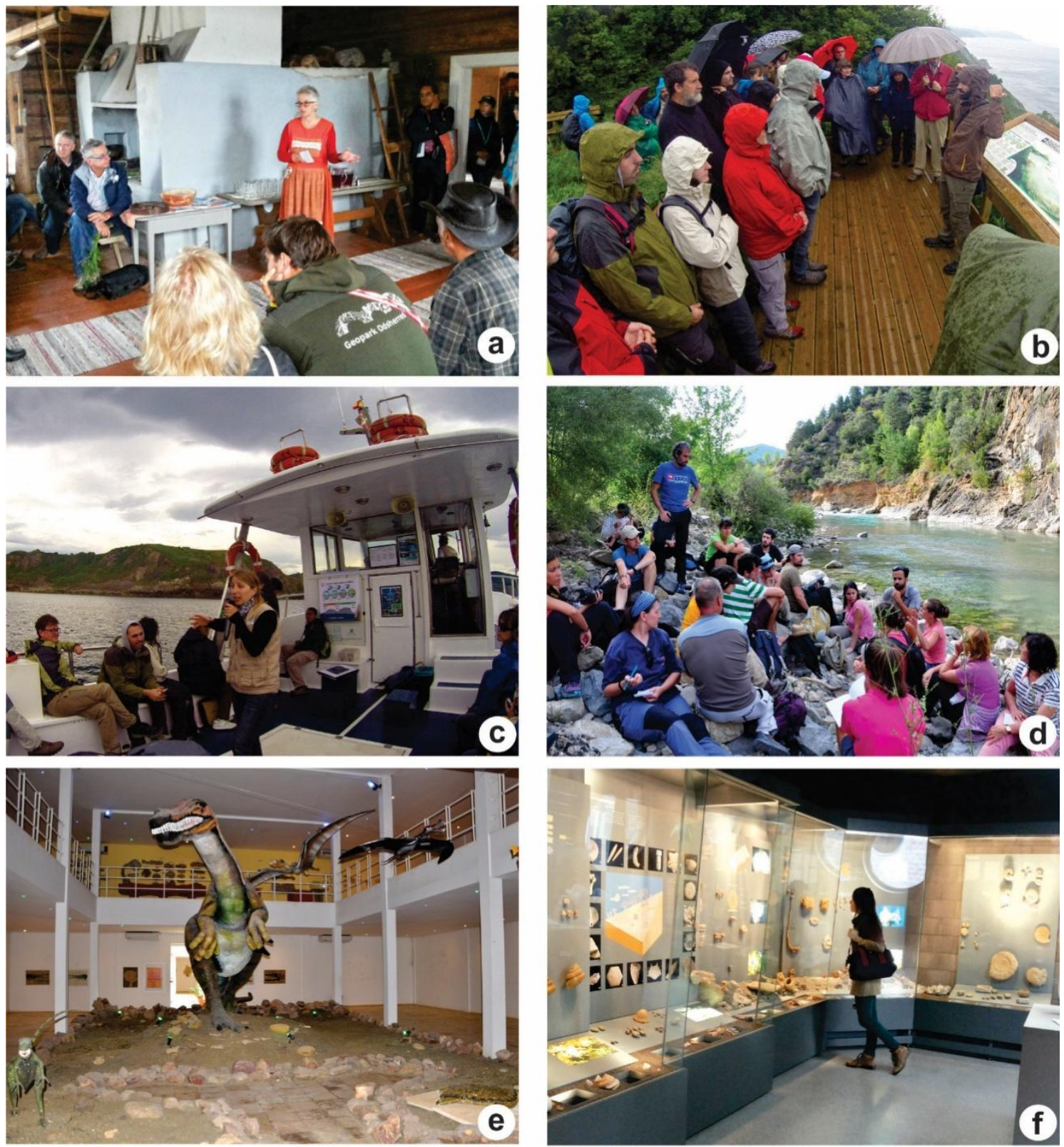

Figura 3: Algumas atividades geoturísticas:

(a) Fazenda - Museu do século XVII RokuaGeopark/Finlândia. (b-c) Saída de campo por terra e mar no Costa Vasca Geopark - Costa Vasca /Espanha. (d) Curso de verão sobre Geoparques e Geoconservação no Geoparque SobrabePirineus /Espanha(a-d @Thaís Guimarães, 2015). (e) Museu de Paleontologia da Urca no GeoPark Araripe /Brasil(@Thaís Guimarães, 2013). (f) Museu na fábrica de cimento HolcimWerkforum Geoparque SchwäbischeAlb/Alemanha (@Jaqueline Gütinken, 2015).

Para os autores, a proposta do geoturismo é agregar o conhecimento geocientífico ao patrimônio natural.

Ainda no âmbito dos pesquisadores brasileiros o geoturismo foi definido por Ruchkys (2007) como: 
Segmento da atividade turística que tem o patrimônio geológico como seu principal atrativo e busca sua proteção por meio da conservação de seus recursos e da sensibilização do turista, utilizando, para isto, a interpretação deste patrimônio tornando-o acessível ao público leigo, além de promover a sua divulgação e o desenvolvimento das ciências da Terra (RUCHKYS, 2007, p. 23).

Por ser um conceito relativamente novo, como já mencionado, e se encontrar em fase de reformulações, pesquisadores de diversos países tentam achar um consenso com relação ao real conceito e objetivos que englobam a atividade geoturística.

Perante este cenário de múltiplos conceitos e interpretações, foi realizado no Arouca Geoparque Mundial da UNESCO, em Portugal, o Congresso Internacional de Geoturismo - "Geotourism in Action - Arouca 2011". Como resultado das reuniões e diversas discussões acerca do tema foi constituída a "Declaração de Arouca", apresentando seis importantes questões sobre a atividade e a essência de como deve ser interpretado e desenvolvido o geoturismo.

Após a Declaração de Arouca, foi proposto, por acordo discutido e acordado entre a Rede Global de Geoparques e o Centro de Turismo Sustentável da NationalGeographicSociety, que o geoturismo deve ser definido como "o turismo que sustenta e incrementa a identidade de um território, considerando a sua geologia, ambiente, cultura, valores estéticos, patrimônio e o bem-estar dos seus residentes." Ficando dessa forma, o turismo geológico como uma das diversas componentes do geoturismo (DECLARAÇÃO DE AROUCA, 2011, p. 1).

O conceito supracitado é mais abrangente e interdisciplinar, prevalecendo, contudo a componente geológica como mais uma peça da complexa engrenagem que é a atividade geoturística. Com base na visão mais holística embutida neste conceito ressalta sua estreita relação com interdisciplinaridade.

O presente trabalho não descarta nenhum dos conceitos expostos. Entretanto, acredita na necessidade de se trabalhar o geoturismo de forma interdisciplinar, com base na componente geológica, correspondente ao meio físico, todavia, levando em consideração os aspectos culturais e socioambientais apresentados por Liccardo e Piekarz (2007) e pela Declaração de Arouca (2011).

\subsection{O Litoral Sul de Pernambuco}


A área de estudo está inserida na Bacia Sedimentar de Pernambuco em sua porção centro-sul, que compreende, de acordo com a divisão político-administrativa do Estado, os municípios do Cabo de Santo Agostinho, Ipojuca, Sirinhaém, Rio Formoso, Tamandaré, Barreiros e São José da Coroa Grande (Fig. 4).

\section{LITORAL SUL DE PERNAMBUCO}

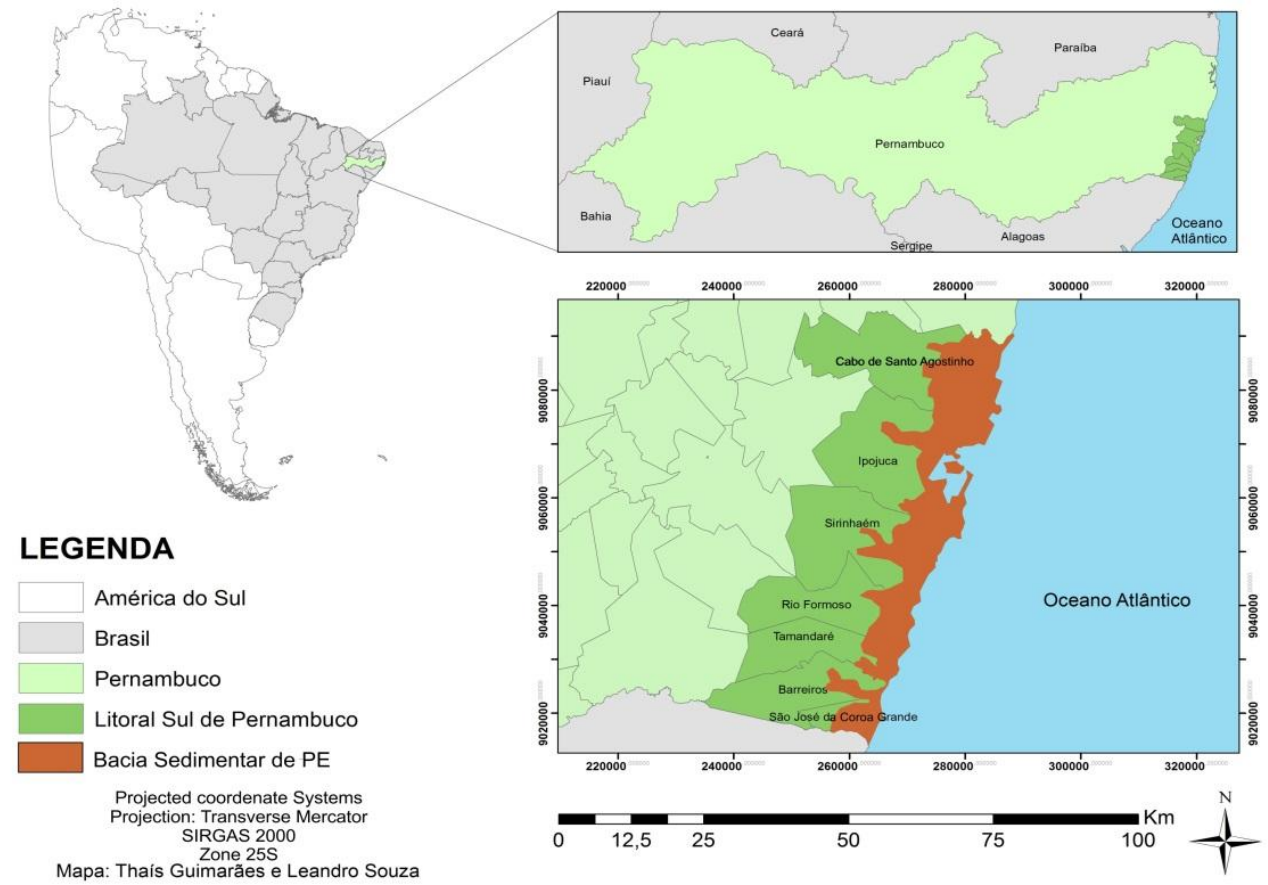

Figura 4: Localização dos municípios do Litoral Sul de Pernambuco e área aproximada da Bacia Sedimentar de Pernambuco aflorante na área de trabalho (Fonte: GUIMARÃES, 2016).

A principal via de acesso ao litoral sul é a BR-101 e, em seguida, a rodovia estadual PE-60, que começa próximo ao centro do Cabo de Santo Agostinho ou a via transoceânica PE-009, sob a administração da concessionária Rota do Atlântico. Outra forma de chegar às praias é pela via litorânea, saindo do Recife pelas praias de Piedade e Candeias em direção Sul até a Ponte do Paiva, que dá acesso ao Litoral Sul através da Reserva do Paiva, já no município do Cabo de Santo Agostinho.

\subsubsection{Geodiversidade e Patrimônio geológico local}

O Litoral Sul está inserido sob o domínio de clima tropical úmido, classificado por Köppen como AS', apresenta alto índice pluviométrico com médias anuais em torno de $1.800 \mathrm{~mm}$. As temperaturas apresentam uma variação entre $23,9^{\circ} \mathrm{C}$ e 
26,6드, com uma média anual de 25,5ㄷ (MOREIRA et al., 2003), fator determinante para o alto índice de intemperismo químico na região.

Os elementos geológicos, geomorfológicos e hidrográficos são os principais responsáveis por essa valorização da paisagem e do território. Foi identificada alguma ocorrência paleontológica, cita-se ainda a diversidade de solos, estes com menos relevância e destaque para a proposta agora apresentada.

O compartimento geológico apresenta litologias e características bastante diversas e únicas na região, dividido em três grandes grupos de rochas: i) Bacia sedimentar de Pernambuco; ii) Suíte Magmática de Ipojuca, que intrude a bacia supracitada; e iii) Rochas do embasamento cristalino, a exemplo das rochas que compreendem o Complexo Pernambuco-Alagoas.

Nesse sentido, destacam-se como principais interesses geológicos os eventos tectônicos associados ao estágio final da separação do mega continente Gondwana, que resultou na configuração atual dos continentes Sul-americano e Africano (LONG et al., 1996). Atenta-se para os elementos mineralógicos e magmáticos associados ao vulcanismo cretáceo nessa região, resultantes em rochas únicas no estado, entre elas riolitos, traquitos, basaltos e ignimbritos (Fig. 5ac).

No que diz respeito às rochas sedimentares, cabe destacar os arenitos de praia (beachrocks), dispostos linearmente em praticamente toda a costa litorânea (Fig. 5d). Tais rochas apresentam elevado valor científico, por refletirem um nível relativo do mar mais alto do que o atual durante o Holoceno (BRANNER, 1904; SUGUIO et al., 2013; GUIMARÃES et al., 2017). 

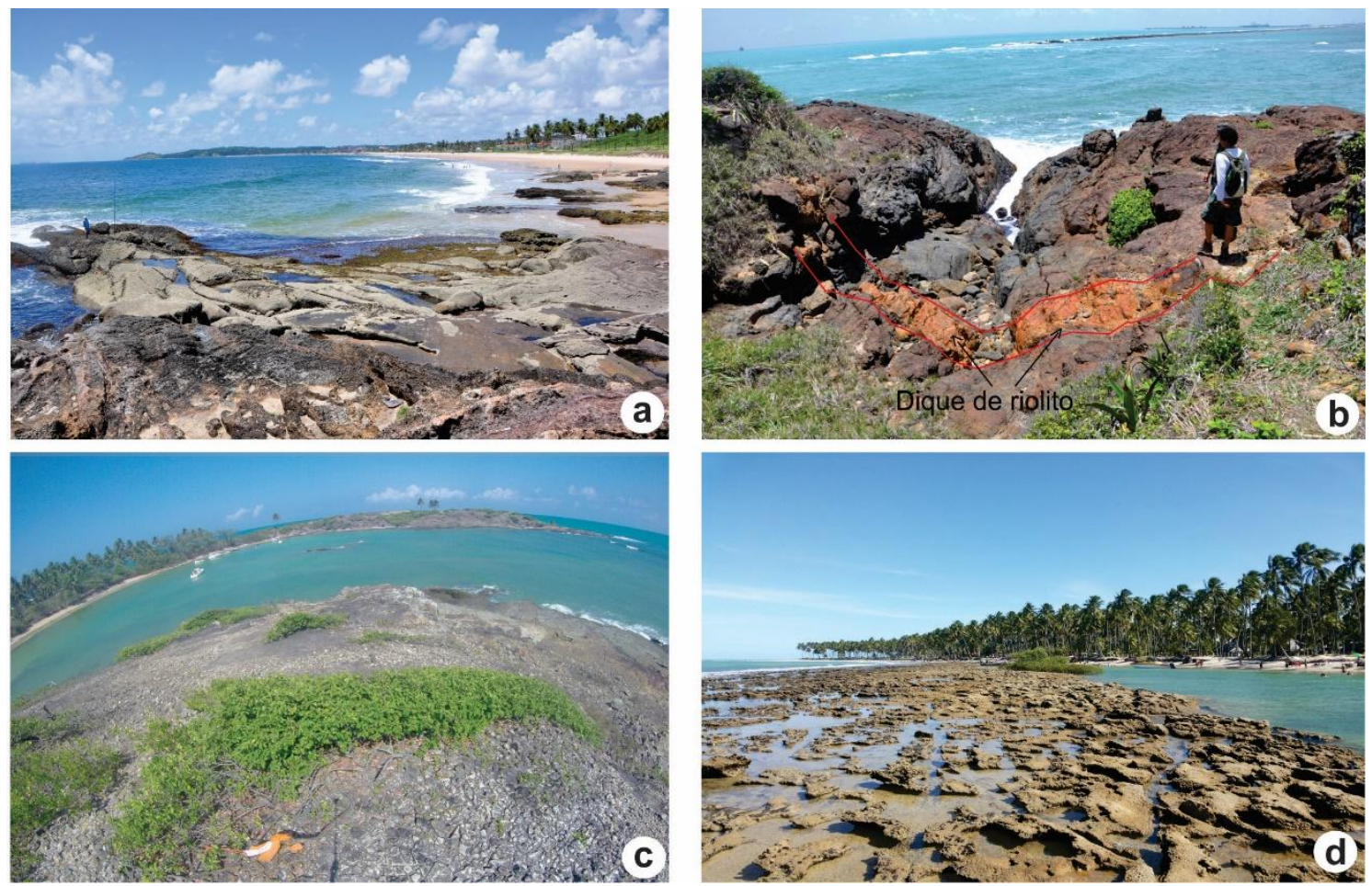

Figura 5: Rochas e paisagens do Litoral Sul de Pernambuco. (a) Derrame de traquitos (rocha vulcânica), ao fundo é possível ver a Praia de Gaibu (Cabo de Santo Agostinho). (b) Dique de riolito (rocha vulcânica) no entorno da Vila de Nazaré(@Thaís Guimarães, 2014). (c) Trecho da llha vulcânica de Santo Aleixo, também formada por riolitos (Sirinhaém). (d) Linha de arenitos de praia ou também chamados de beachrocks (rochas sedimentares) na Praia de Carneiros (Tamandaré) (@Thaís Guimarães, 2016).

No que se refere aos recursos minerais, não existem minas ou grandes pedreiras. Contudo, as ruínas históricas são testemunhas do uso das rochas graníticas e dos arenitos de praia extraídos e utilizados nas edificações do período colonial. Cavas abandonadas também evidenciam a exploração de argila, a exemplo do Cabo de Santo Agostinho, onde atualmente funciona o banho de argila de Gaibu (Fig. 6a).

Geomorfologicamente a geodiversidade se destaca através de uma configuração geográfica heterogênea e visivelmente distinta dos setores costeiros: Metropolitano e Norte do Estado. Uma marcante característica da região é o relevo ondulado formado por morros, colinas e vales (CPRH, 2001) (Fig. 6b).

Destacam-se ainda no compartimento geomorfológico local as planícies fluviais, compostas por várzeas e terraços dos rios da região. Em sua porção leste, margeando a linha de costa, tem a planície costeira de origem sedimentar e resultante do conjunto de ações marinhas e fluviais. Entre as formas e feições geomorfológicas moldadas ao longo dos anos veem-se praias, restingas, 
manguezais e várzeas fluviais alagadas (CPRH, 2001; PFALTZGRAFF, 2007) (Fig. $6 c-d)$.

Quanto a rede hidrográfica a região apresenta importantes áreas estuarinas que vão desde o estuário do Rio Jaboatão, ainda no município do Cabo de Santo Agostinho ao município de São José da Coroa Grande, representados por rios importantes como: rio Jaboatão, rio Massangana, rio Ipojuca, rio Maracaípe, rio Sirinhaém, rio Arinquindá, rio Formoso e rio Una. A dinâmica hidrográfica molda a paisagem ao longo dos canais e ilhas fluviais até os estuários e desembocaduras (SILVA et al., 2011).
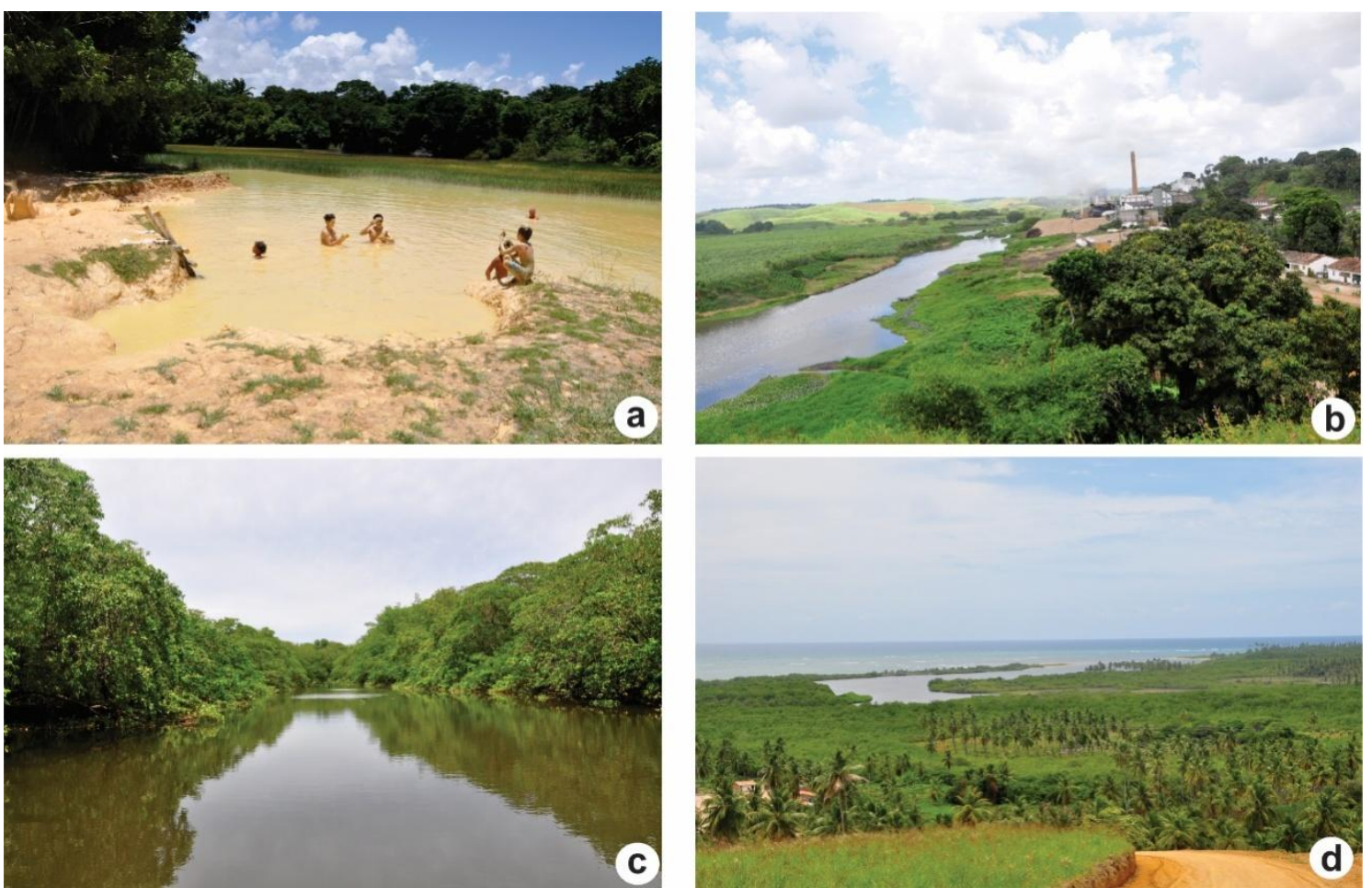

Figura 6: Paisagens do Litoral Sul de Pernambuco. (a) Banho de argila de Gaibu. (b) Paisagem de vales e morros, com destaque para o Rio Ipojuca e Usina de mesmo nome às margens direita do rio. (c) manguezal no distrito da Várzea do Una (São José da Coroa Grande). (d) Vista para planície e Foz do Rio Una (Várzea do Una - São José da Coroa Grande) (@Thaís Guimarães, 2016).

No que se refere ao patrimônio geológico de uma área ou região, é necessário que se elabore todo um planejamento para a realização de um inventário deste patrimônio. Tal documento se configura como embasamento para a implantação de quaisquer estratégias de geoconservação e geoturismo em um determinado território.

O inventário tem como objetivos, por exemplo, viabilizar a aplicação de análises qualitativas e quantitativas dos elementos que compõem o patrimônio

Ciência e Sustentabilidade - CeS / Juazeiro do Norte, v. 3, n. 1, p. 33-57, jan/jun 2017 
geológico dessas áreas, avaliando características distintas, como cientificidade, raridade, vulnerabilidade, condições de acesso e/ou potencial turístico, entre outros. Aos elementos inventariados dá-se o nome na literatura de geossítios.

No Litoral Sul de Pernambuco foi realizado um inventário inicial pelo serviço geológico do Brasil (NASCIMENTO et al., 2012) e com base neste primeiro documento, foi feita uma ampliação da área e aplicada novas metodologias de avaliação o que resultou para este novo território um patrimônio geológico de 13 geossítios, classificados qualitativa e quantitativamente (GUIMARÃES, 2016) (Tab. 1).

Tabela 1. Lista dos geossítios inventariados no Litoral Sul de Pernambuco e suas principais características. $(\mathrm{CSA}=$ Cabo de Santo Agostinho $/ \mathrm{SJCG}=$ São José da Coroa Grande / SMJ = Suíte Magmática Ipojuca / BSPE = Bacia Sedimentar de PE) (Fonte: Guimarães,

\begin{tabular}{|c|c|c|c|c|c|}
\hline № & GEOSSÍTIO & TIPOLOGIA & $\begin{array}{c}\text { CATEGORIAS } \\
\text { (FRAMEWORKS) }\end{array}$ & MUNICÍPIO & $\begin{array}{l}\text { COORDENADAS UTM } \\
\text { 25L }\end{array}$ \\
\hline G1 & Pedras Pretas & Seção & SMJ & CSA & $285377 / 9081828$ \\
\hline G2 & Banho de Argila de Gaibu & Ponto & BSPE & CSA & $283503 / 9081480$ \\
\hline G3 & Promontório do Cabo & $\begin{array}{c}\text { Área } \\
\text { complexa }\end{array}$ & SMJ / BSPE & CSA & $285786 / 9076024$ \\
\hline G4 & Neck Vulcânico da Usina Ipojuca & Área & SMJ & Ipojuca & $270292 / 9071562$ \\
\hline G5 & Beachrocks de Muro Alto & Seção & BSPE & Ipojuca & $282690 / 9068246$ \\
\hline G6 & $\begin{array}{c}\text { Rocha Vulcânica Piroclástica do } \\
\text { Engenho Saco }\end{array}$ & Área & SMJ & Ipojuca & $271778 / 9067920$ \\
\hline G7 & $\begin{array}{l}\text { Piscinas Naturais de } \\
\text { Porto de Galinhas }\end{array}$ & Área & BSPE & Ipojuca & $279951 / 9058706$ \\
\hline G8 & Ilha Vulcânica de Santo Aleixo & Área & SMJ & Sirinhaém & $277412 / 9047371$ \\
\hline G9 & $\begin{array}{l}\text { Formas e Meandros do } \\
\text { Rio Formoso }\end{array}$ & $\begin{array}{c}\text { Área } \\
\text { complexa }\end{array}$ & BSPE / SMJ & $\begin{array}{c}\text { Rio } \\
\text { Formoso/ } \\
\text { Sirinhaém }\end{array}$ & 269778/9039265 \\
\hline G10 & $\begin{array}{l}\text { Arenitos Algálicos da Praia dos } \\
\text { Carneiros }\end{array}$ & Seção & BSPE & Tamandaré & 271322/9037269 \\
\hline G11 & Cachoeira da Bulha & Ponto & Complexo PE/AL & Tamandaré & $262905 / 9033610$ \\
\hline G12 & Trilha das Geoformas & $\begin{array}{c}\text { Área } \\
\text { complexa }\end{array}$ & Complexo PE/AL & Barreiros & $266166 / 9024724$ \\
\hline G13 & Estuário e Várzea do Una & $\begin{array}{c}\text { Área } \\
\text { complexa }\end{array}$ & $\begin{array}{l}\text { BSPE / Complexo } \\
\text { PE/AL }\end{array}$ & $\begin{array}{l}\text { Barreiros/ } \\
\text { SJCG }\end{array}$ & $265655 / 9020258$ \\
\hline
\end{tabular}

2016)

\subsubsection{Aspectos históricos e culturais}

A região no período que antecedeu o descobrimento do Brasil pelos portugueses em 1500, foi habitada pelos índios Caetés do grupo Tupi. Já com relação ao descobrimento, alguns historiadores defendem a versão de que em 26 de janeiro de 1500, período que precedeu o descobrimento oficial por Pedro Alvares Cabral, alguns navegadores espanhóis, capitaneados pelo espanhol Vicente YañezPizón, teriam ancorado na área hoje denominada como Cabo de Santo Agostinho (IZQUIERDO LABRADO, 2003). 
Trata-se de um debate histórico no qual há muitas divergências. Entretanto, alguns cabenses, com o apoio do historiador espanhol JuliolzquierdoLabrado acreditam na versão de que Pizón teria sido o primeiro europeu a pisar em território brasileiro. Mesmo se tratando de hipóteses e versões não comprovadas, muitos cabenses não só acreditam como propagam o suposto descobrimento. Há no município escolas e estabelecimentos comerciais cujo nome homenageia o espanhol Vicente YañezPizón.

Mais tarde, já no século XVII a região foi palco das diversas investidas dos holandeses, onde a configuração geográfica foi fator determinante para a defesa do território, onde foram edificadas sobre o promontório do Cabo de Santo Agostinho instalações militares. Tais construções contribuíram para a resistência luso-brasileira durante as tentativas de tomada do território pelo litoral. Apesar disso, em 1630 os holandeses alcançaram o território e obtiveram o controle da entãocapitania hereditária dePernambuco, ou Nova Lusitânia, como também era chamada, até o ano de 1654.

A maioria das edificações continua de pé e mesmo em ruínas podem ser visitadas, entre elas as ruínas do Forte Castelo do Mar (Séc. XVII), do Forte São Francisco Xavier (Séc. XVII), do Quartel Velho (Séc. XVII) e a mais recente, Casa do Faroleiro (Séc. XIX). Todas estão localizadas sobre o promontório do Cabo, próximo à histórica Vila de Nazaré, onde ainda resistem ao tempo a igreja homônima e as ruínas do antigo convento Carmelita (Fig. 7a-b).

Ainda do ponto de vista histórico destaca-se o Forte de Santo Inácio de Loyola (Século XVII) e o Farol de Tamandaré, ambos no município homônimo, igrejas antigas, a exemplo da igreja de São Pedro (século XIX), em estilo barroco,localizada a beira mar na praia de Campas (Tamandaré) e os engenhos de cana-de-açúcar, com desataque para o engenho Massangana, onde pode ser visitada a casa grande, a igreja (capela de São Mateus) localizada no alto de uma colina e parte do antigo moinho movido por tração animal (Fig. 7c-d). 

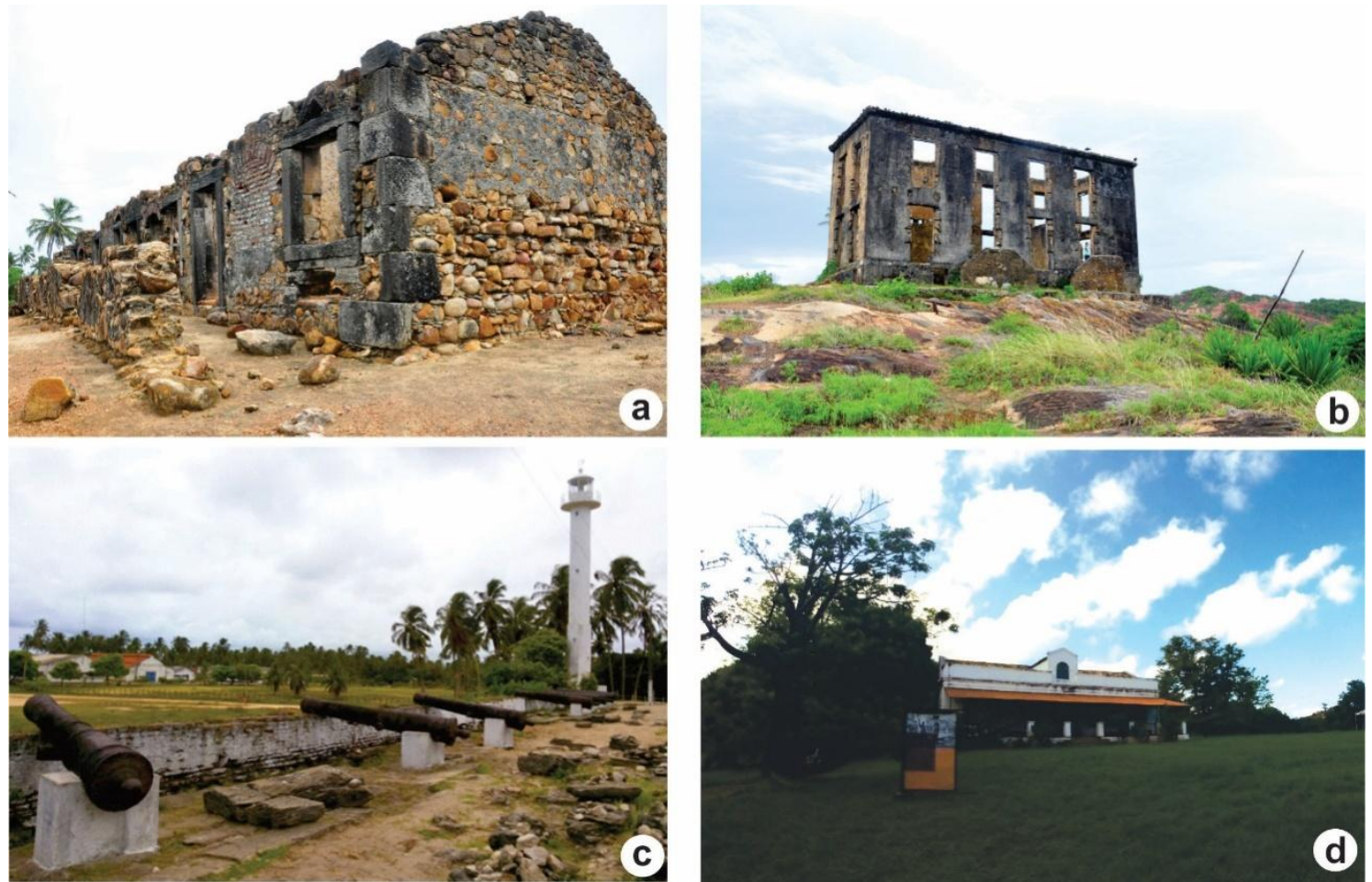

Figura 7: Patrimônio histórico e arqueológico. (a) Ruinas do quartel velho - Vila de Nazaré (@Thaís Guimarães, 2014). (b) Ruínas da casa do faroleiro - Vila de Nazaré. (d) Área externa do Forte de Santo Inácio de Loyola - Tamandaré. (d) Vista para o casarão do engenho Massangana, transformado em museu (Cabo de Santo Agostinho) (@Thaís Guimarães, 2016).

\subsubsection{Evolução do turismo}

No Brasil o hábito de frequentar a praia e tomar banho de mar inicia-se por meio da medicina. Em Pernambuco, o período entre 1840 e 1940 foi marcado pelo surgimento da prática dos banhos salgados entre a população. É ainda neste período que as praias se consolidam como um lugar de cura, recreação e de convívio social, o que até pouco antes ocorria por meio dos banhos de rios (ARAÚJO, 2006).

Conforme o autor supracitado partir de 1940 viu-se uma fase de expansão urbana em Recife e Olinda e que depois se estendeu às demais praias do litoral pernambucano. Tal crescimento urbano na faixa litorânea foi incentivado pela industrialização no pós-guerra, entretanto, se deu principalmente pelo fenômeno da "segunda residência". As residências de veraneio são consideradas como o fator mais expressivo da urbanização litorânea.

Nesse sentido, têm-se como origem da atividade turística no Litoral Sul de Pernambuco o fenômeno das segundas residências, que modificou a paisagem, preteritamente composta por extensas fazendas de coqueiros e vilas de pescadores, 
e que se transformaram em grandes áreas de loteamentos para construção de casas de veraneio, empreendimentos hoteleiros e, consequentemente, comércios e bens de serviços para atender a população flutuante (ARAÚJO, 2006; 2013).

O Litoral Sul de Pernambuco apresenta como atrativos turísticos a "beleza cênica natural", decorrente de sua configuração geológica e geográfica, bem como os diversos ecossistemas, com a possibilidade de navegar entre manguezais ou percorrer algumas trilhas contemplando os resquícios de Mata Atlântica.

Todavia, destacam-se como principal atrativo da região as praias de águas quentes e, em sua maioria, calmas, o que configura a atividade turística como turismo de "sol e praia", definida pelo Ministério do Turismo como "atividades turísticas relacionadas à recreação, entretenimento ou descanso em praias, em função da presença conjunta de água, sol e calor" (BRASIL, 2010, p. 14).

Dessa forma, mesmo com o turismo de sol e praia já consolidado vê-se que alguns valores que poderiam estar agregados, como a forte carga histórica e cultural. A influência dos povos indígenas e, principalmente, africanos é marcante na região, esta, diretamente ligada ao cultivo da cana-de-açúcar e trabalho escravo nos engenhos. Atualmente existem no Litoral Sul de Pernambucoduas comunidades Quilombolas, as comunidades “Onze Negras”, localizada no município do Cabo de Santo Agostinho, e "Engenho Siqueira", no município de Rio Formoso.

Como mencionado anteriormente, a atividade turística atual é caracterizada como turismo de sol e praia, aonde boa parte dos visitantes já chegam com pacotes turísticos pré-definidos por agências ou resorts.

Para a outra grande parcela, que viaja por conta própria, não há incentivos suficientes para fazer outros roteiros que não sejam os bares à beira mar, passeios de barco, mergulhos ou atividades náuticas como passeios de caiaques e em pranchas de stand uppaddle, ou seja, todas as atividades são voltadas para o turismo "sol e praia", desconsiderando todo o potencial geoturístico que o território apresenta (científico, educativo, histórico, cultural...)(GUIMARÃES, 2016).

Outro ponto observado na região é a produção e comércio de produtos locais, a exemplo do artesanato, doces e licores feitos com frutas da estação e outros elementos da gastronomia (Fig. 8a-d). Tais atividades podem ser trabalhadas igualmente de forma integrada com os pilares do geoturismo. Entretanto, para isso é necessário que se valorize esses produtos locais, incentivando a produção e a 
melhoria na qualidade, utilizando a criatividade e os elementos do território como diferencial.

Sugestões de rótulos com referências sobre a geologia ou história local, por exemplo, ou ainda cardápios em restaurantes que trouxessem nomes das rochas locais, relevos, comunidades, bem como artesanatos em alusão aos eventos históricos e/ou geológicos, são pequenos exemplos que possibilitam valorizar os produtos da região.

Para o desenvolvimento do geoturismo se faz necessário a informação e o conhecimento dos elementos naturais, históricos e socioambientais locais. Há de haver uma política de capacitação para os profissionais envolvidos, estendidos ainda a comunidade, para que os mesmos ao adquirir o conhecimento possam valorizar seu território e sentir o prazer de passar as informações adiante.
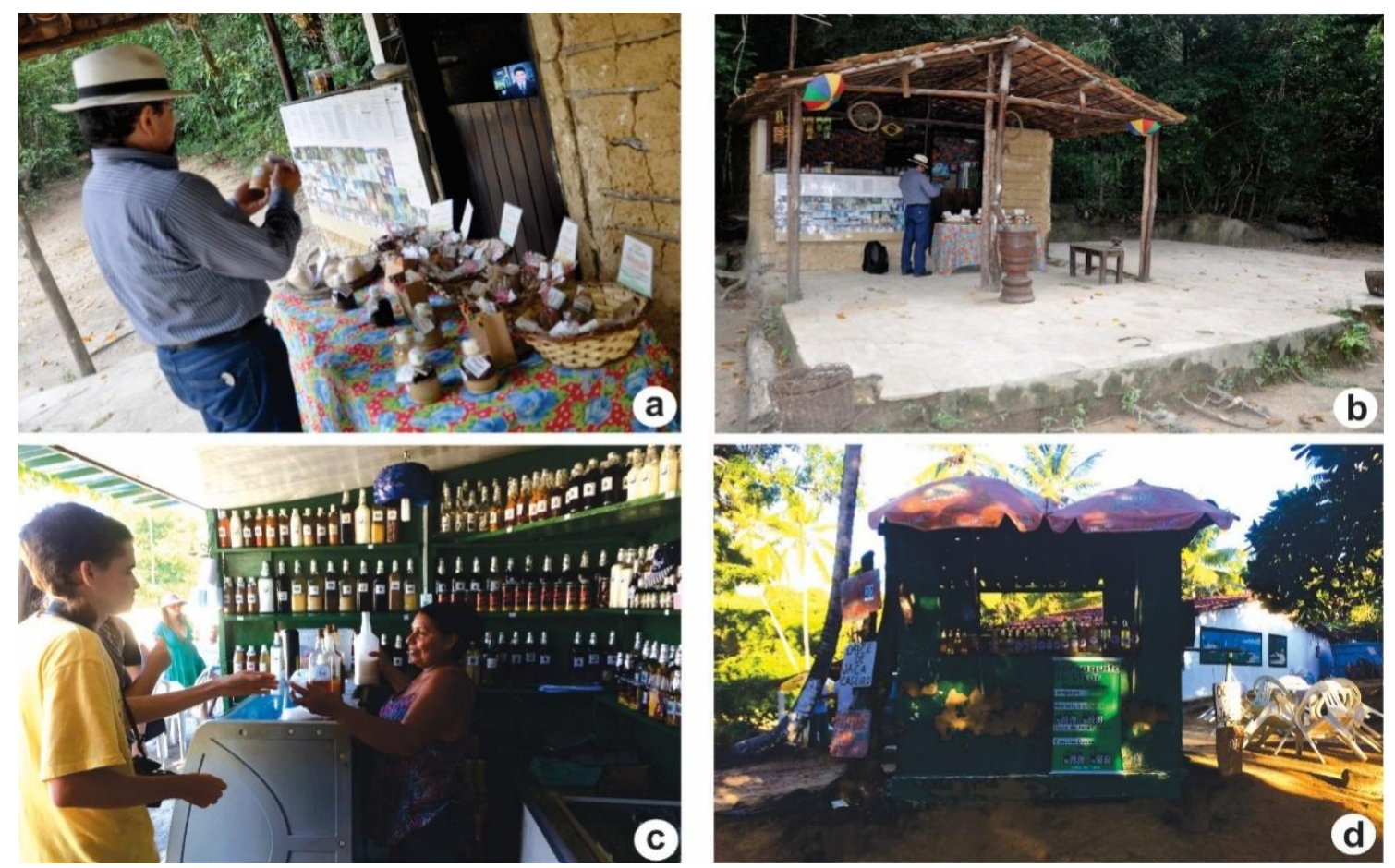

Figura 8: Venda de produtos artesanais. (a-b) Produtos feitos com argila, como sabonetes e esfoliantes (Banho de argila de Gaibu - Litoral sul de PE) (@Thaís Guimarães, 2014). (c) Comércio de licores, doces e cachaças artesanais na Vila de Nazaré (Cabo de Santo Agostinho). (d) Estrutura artesanal utilizada para vender produtos locais como doces e licores próximo a praia de Calhetas (Cabo de Santo Agostinho) (@Thaís Guimarães, 2017).

Sugere-se que aos passeios já existentes, como os de barcos e bugres, guiados por agências sejam acrescidas informações sobre a história geológica da terra, a formação da paisagem. Explicar de forma simples, por exemplo, porque 
aqueles arenitos de praia (beachrocks) estão dispostos linearmente em quase toda costa, mostrar que eles representam mais que simples piscinas naturais.

Para isso, podem ser confeccionados pelas operadoras de turismo materiais em papel sulfite ou cartolinas, explicando de maneira didática a configuração da faixa litorânea, para obter maior duração o material pode ser plastificado. É possível desenvolver atividades em trilhas, inserir sinalização nos principais pontos de interesse, produzir folders e cartazes, bem como confeccionar produtos (souvenires) temáticos a fim de gerar renda extra (Fig. 9a-f).

Nesse sentido, ao analisar as caraterísticas e possíveis produtos turísticos nessa região, vê-se um território que soma um patrimônio natural de destaque, seja por seus ecossistemas, beleza cênica ou importância científica, associado a relevante valor histórico e cultural. Apresentando, portanto, todas as características e possibilidades para que se mantenha o turismo de sol e praia e incremente a esta atividade os princípios e pilares do geoturismo. 

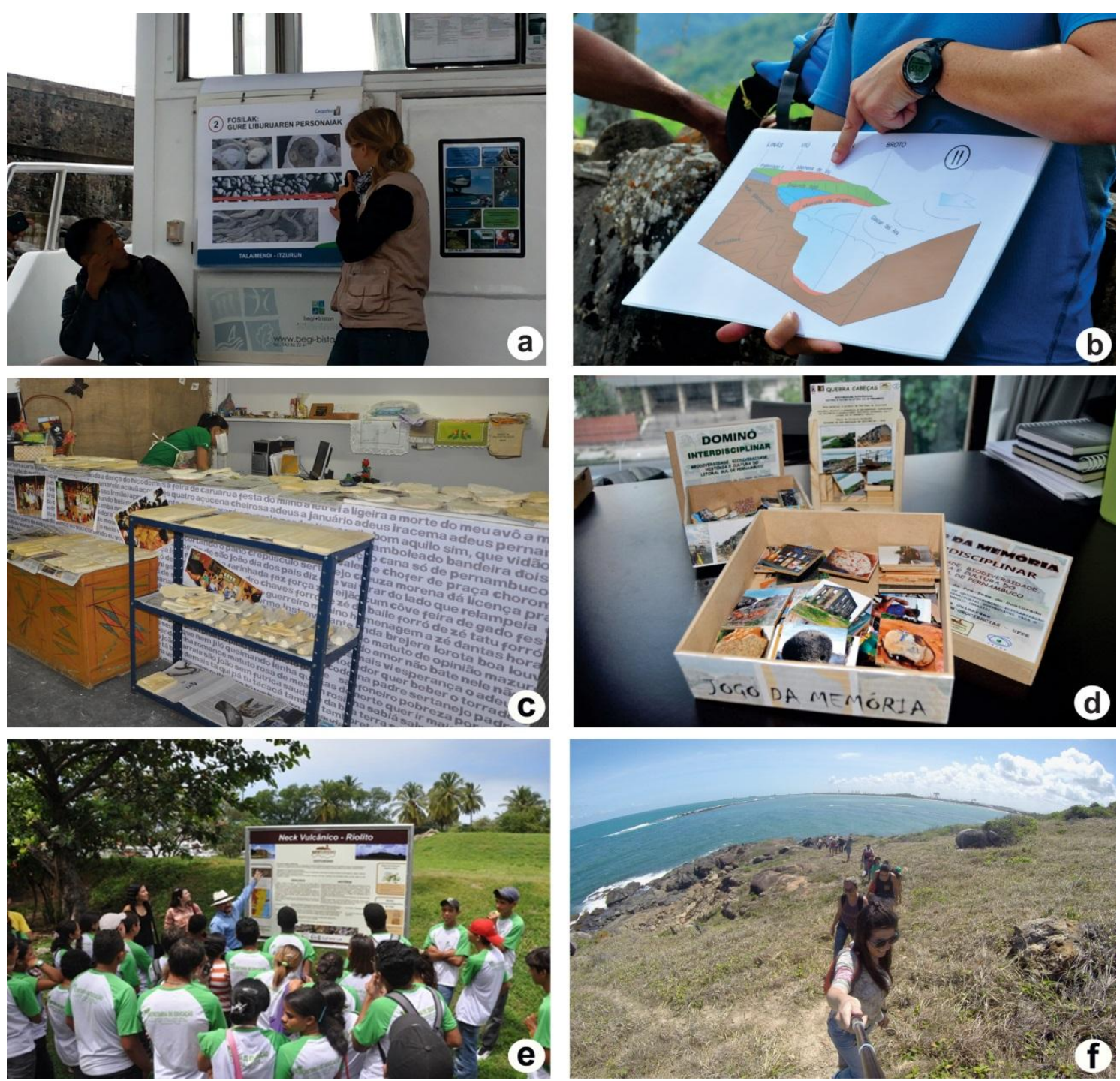

Figura 9: Exemplos de atividades e materiais de apoio ao geoturismo. (a) Material ilustrado utilizado em passeio de barco para explicar aos visitantes como se desenvolveu a paisagem na região do Geoparkea (Costa Vasca - ES). (b) Material ilustrado também utilizado para explicar os processos geológicos e configuração da paisagem (Geoparque Sobrarbe-Pirinéus) (@Thaís Guimarães, 2015). (c) Confecção e venda de réplica de fósseis em gesso no Geoparque Araripe. A iniciativa visa movimentar a economia e conscientizar as pessoas sobre a importância dos fósseis (@Thaís Guimarães, 2014). (d) Jogos geoeducativos desenvolvidos com a temática do Litoral Sul de Pernambuco (GUIMARÃES ET AL., 2017). (e) Painéis informativos com informações acerca da geologia do Litoral sul de Pernambuco fixadas no museu e espaço ciência em Olinda - PE (@Rogério Valença, 2013). (f) Atividade de campo promovida através de trilhas geoeducativas sobre o promontório do Cabo no município de Cabo de Santo Agostinho - PE (@Thaís Guimarães, 2016).

\section{CONSIDERAÇÕES FINAIS}

O conceito de território é bastante complexo e não há de fato um consenso do que realmente consiste um território. Nesse sentido, é a partir de um espaço preexistente que se iniciam as relações sociais e econômicas que consequentemente resultarão em um determinado território. 
No presente trabalho este território compreende a faixa litorânea Sul de Pernambuco, com toda sua territorialidade, onde estão sendo abordadas possibilidades de ações e estratégias que possam contribuir para seu desenvolvimento sustentável.

O Litoral Sul de Pernambuco se apresenta como um território histórico e promissor, importante do ponto de vista cultural e socioeconômico, que possui acima de tudo um patrimônio geológico de relevância internacional. Por outro lado, apresenta também muitas desigualdades socioeconômicas e possíveis riscos de perder sua identidade sociocultural, bem como comprometer seus elementos naturais, sejam eles bióticos ou abióticos.

Trabalhos prévios já foram desenvolvidos na região. Foi elaborado o inventário do patrimônio geológico, a confeccionado material educativo e informativo por meio de cartilha, folders e jogos, bem como apresentadas sugestões de intervenções estruturais e não estruturais,

Este trabalho apresenta uma proposta de desenvolvimento territorial sustentável, através do emprego de estratégias de geoconservação e promoção do geoturismo, utilizando, por exemplo, as ferramentas já existentes e incentivando o avanço de novas pesquisas.

Em qualquer território, onde haja geodiversidade e patrimônio geológico relevante, bem como, comunidades vivendo e promovendo suas atividades, é possível promover uma atividade turística interdisciplinar, de desenvolvimento territorial sustentável, que agregue valor à atividade preexistente de forma integradora, participativa e norteada pelos princípios do geoturismo.

\section{AGRADECIMENTOS}

Os autores agradecem a Coordenação de Aperfeiçoamento de Pessoal de Nível Superior (CAPES) pelo investimento e apoio financeiro dado ao projeto de doutorado e intercâmbio (PDSE), realizado na Universidade de Trás-os-Montes e Alto Douro (Portugal), concedido a Thaís Guimarães e que possibilitou o desenvolvimento desta pesquisa. Nossos agradecimentos a Revista Ciência e Sustentabilidade pelo trabalho de divulgação da Ciência e incentivo ao turismo sustentável.

Ciência e Sustentabilidade - CeS / Juazeiro do Norte, v. 3, n. 1, p. 33-57, jan/jun 2017 


\section{REFERÊNCIAS}

ARAÚJO, R. C. B. A vida ao ar livre: Os banhos de rio, de mar e de sol. CLIO Revista de Pesquisa Histórica. N. 24, v. 2. 2006.

ARAÚJO, R. C. B. A cultura da praia: urbanização, sociabilidade e lazer no Brasil, 1840-1940. Acta Científica XXIX Congreso de la Asociación Latinoamericana de Sociología. Facultad de CienciasSociales de Chile. p1-8. 2013. Disponível em: $<$ http://actacientifica.servicioit.cl/biblioteca/gt/GT23/GT23 deCassiaBarbosa.pdf > Acesso em 03 de fevereiro de 2016.

BOFF, L. Tempo de transcendência: o ser humano como um projeto infinito. Rio de Janeiro: Sextante, 2000.

BRANNER, J. C. The stone reefs of Brazil their geological and geographical relations with a chapter on the coral reefs. Museum of Comparative Zoology, Bull. Harvard College, Cambridge, v.44 (geol.ser.n.7).1904.

BRASIL. Ministério do Turismo, Secretaria Nacional de Políticas de Turismo, Departamento de Estruturação, Articulação e Ordenamento Turístico, CoordenaçãoGeral de Segmentação. Sol e Praia: orientações básicas.. - 2.ed - Brasília: Ministério do Turismo. 2010.59p.

BRILHA, J.Patrimônio Geológico e Geoconservação: a conservação da natureza na sua vertente geológica. Braga:Palimage Editores, 2005.

BUCKLEY, R. Environmental Inputs and Outputs in Ecotourism: Geotourism with a Positive Triple Bottom Line? Journal of Ecotourism, 2:1, 76-82. 2003. To link to this article: http://dx.doi.org/10.1080/14724040308668135.

CPRH. Diagnóstico Socioambiental do Litoral Sul de Pernambuco. Agência Estadual do Meio Ambiente - CPRH. Recife. 89p.2001.

DECLARAÇÃO DE AROUCA. Declaração de Arouca. Congresso Internacional de Geoturismo - "Geotourism in Action - Arouca 2011. Disponível em: http://www.geoparquearouca.com/geotourism2011/adm/upload/30.declaracao de ar ouca pt.pdf. 
GRAY, M. Geodiversity: valuing and conserving abiotic nature. John Wiley and Sons, Chichester, England.2004.

GRAY, M. Geodiversity: the origin and evolution of a paradigm. In: Burek, C.V. \& Prosser, C.D. (eds) The history of Geoconservation. The GeologicalSociety, London, SpecialPublications, 300, p. 31-36. 2008.

GUIMARÃES, T. O. Patrimônio geológico e estratégias de geoconservação: popularização das geociências e desenvolvimento territorial sustentável para o Litoral Sul de Pernambuco (Brasil). Tese de Doutorado apresentada ao departamento de geológica da UFPE. Recife/Pe. 2016. 406p.

HOSE, T. A. Selling the Story of Britain's Stone.Environmental Interpretation. V. 10, n2, p 16-17. 1995.

HOSE, T. A. "Geoturismo" europeo. Interpretación geológica y promoción de la conservación geológica para turistas.In: BARRETINO, D; WINBLEDON, W.A.P; GALLEGO, E. (eds). Patrimonio geológico: conservación y gestión. Madrid: Instituto Tecnológico Geominero de España, 2000. 212p.

IBGE. Censo demográfico de 2010. Instituto Brasileiro de Geografia e Estatística. Disponível em: http://www.ibge.gov.br/estadosat/perfil.php?sigla=pe\# Acesso em 12 de maio de 2014.

IZQUIERDO LABRADO, J.EI descubrimiento del Brasil por Vicente Yáñez Pinzón: el Cabo de Santo Agostinho. Huelva em su historia. 2ª época VOL 10 - P. 171-941 - Universidad de Huelva. 2003.

LONG, L. E.; SIAL, A. N.; EKVANIL, H. E.; BORBA, G.S. Origin of granite at Cabo de Santo Agostinho - Northeast - Brasil.Contributions to mineralogy and petrology, 92:341-350. 1986.

KOZLOWSKI, S. Geodiversity. The concept and scope of geodiversity. Przeglad Geologiczny, v. 52, n. 8/2, p.833-837, 2004.

MOREIRA, F. M., SANTOS, A. S., MELO, C. R., ALMEIDA, I. S. E ARAÚJO, L. M. N. Hidrologia.In:Sistema de Informações Geoambientais da Região Metropolitana do Recife - CPRM. Recife. 2003. 
NASCIMENTO, M.L., VALENÇA, R.F.E., WILDNER, W. Litoral Sul de Pernambuco (PE) In: Geoparques do Brasil: propostas. Schobbenhaus C e Silva CR. Rio de Janeiro, 1:647-686. 2012.

PFALTZGRAFF, P.A.F. Mapa de suscetibilidade a deslizamentos na Região Metropolitana do Recife. Tese de doutorado apresentada ao programa de PósGraduação em Geociências - CTG - UFPE. Recife/PE. 2007.

PIEKARZ, G.; LICCARDO, A. Turismo Geológico na rota dos tropeiros. Global Tourism. Vol. 3, № 2. Novembro de 2007. ISSN: 1508-558X. Disponível em www.periodicodeturismo.com.br.

RUCHKYS, U. A. Patrimônio Geológico e Geoconservação no Quadrilátero Ferrífero, Minas Gerais: potencial para a criação de um geoparque da UNESCO. Instituto de Geociências, Universidade Federal de Minas Gerais. Belo Horizonte. Tese de Doutorado, 211p. 2007.

SACHS, I. Desenvolvimento includente, sustentável, sustentado. Rio de Janeiro: Garamond. 2004.

SERRANO E.; RUIZ-FLANO, P. Geodiversity. A theoretical and applied coneept.Geographica Helvetica Jg. 62 2007/Heft3. 2007.

SILVA, J. B; GALVÍNCIO, J. D; CORRÊA, A. C. B; SILVA, D. G; MACHADO, C. C. C. Classificação Geomorfológica dos Estuários do Estado de Pernambuco (Brasil) com Base em Imagens do LANDSAT 5/TM. Revista Brasileira de Geografia Física 01:118-133. 2011.

STANLEY, M. Geodiversity. In: Earth Heritage. 14: 15-18. 2000.

SUGUIO, K.; BARRETO, A. M. F.; OLIVEIRA, P. E.; BEZERRA, F. H. R.; VILELA, M. C. S. H. Indicadores de variações holocênicas do nível do mar ao longo da costa dos estados de Pernambuco e Paraíba, Brasil. Revista do Instituto de Geociências USP. Sér. cient., São Paulo, v. 13, n. 4, p.14-152. 2013.

ZWOLINSKI, Z; NAJWER, A; GIARDINO, M. Methods of geodiversity assessment and theirs application. Geophysical Research Abstracts. Vol. 18, EGU2016-15434, 2016. 